\title{
The concept of technogenic risks of a mining transport complex as a tool of lowering the level of its ecological load
}

\author{
Vyacheslav Zhdanov ${ }^{*}$, Andrey Kosolapov ${ }^{1}$, and Flyura Ibragimova ${ }^{2}$ \\ ${ }^{1}$ T.F. Gorbachev Kuzbass State Technical University, Department of Automobile Transportation, \\ 650000 Kemerovo, 28 Vesennyaya st., Russian Federation \\ ${ }^{2}$ Kazakh Humanitarian Juridical Innovative University, Semey, Abaya st., 94, Kazakhstan
}

\begin{abstract}
The article considers the basic provisions of the concept of technogenic risks of a mining transport complex in order to solve the problem of lowering the level of its ecological load. The concept of the ecology of operational environment at open-pit works is introduced, as well as, the structure of the technogenic risk function of a mining transport complex is determined to implement the concept. The article emphasizes the necessity of a systematic approach to the solvation of the problem of lowering the level of the ecological load of a mining transport complex, which should take into account all aspects of negative impact on operational environment. The practical methodology of providing the required ecology of mining transport operational environment is provided.
\end{abstract}

\section{Introduction}

Kuzbass is the largest center of mining industry in our country [1]. Extraction is done by underground method in mines, as well as, by surface method in open pits. The increase in open pits' output complicates mining transport operation conditions since work intensity rises, the extraction depth grows, and etc. It leads to the deterioration of ecological situation in the area of mining transport operation: dust content rises and emissions of harmful substances increase [2]. The necessity to conduct the activities in order to improve the ecological situation at open pits occurs. It is absolutely obvious that the problem of lowering the grade of ecological load cannot be solved by single-type activities, a systematic approach, including the whole complex of technical, organizational and economic measures, is required [3]-[6].

At the same time, the principle of ecological compatibility and population health is used to implement the Strategy of socio-economic development of Kemerovo region, also referred as Kuzbass, for the period to 2035 (Strategy 2035) as one of the basis of its development and realization. Consequently, all anthropogenic sources of a negative impact on the environment, including mining transport complexes, are to be critically analyzed for the compliance with the mentioned above principle.

* Corresponding author: zhvl.ap@kuzstu.ru 
According to Strategy-2035, the principle of ecological compatibility presupposes the development of comfortable environment for the population on all possible territories in daily life, as well as at work. Then, according to the context, the definition of ecology is to be considered in a broader sense when ecology is understood as the formation of general favourable conditions for a society [7]-[8]. In this case, the ecology of social environment will be realized by the complex of measures, directed towards the improvement of the living conditions in residential areas of cities and urban agglomerations [9]-[11]. Similarly, the concept of the ecology of operational environment, considered as the formation of favourable working conditions, is to be introduced in order to fulfill the principle of ecological compatibility and population health of Strategy 2035. The ecology of operational environment is becoming particularly relevant for mining transport in open-pit mining in Kuzbass [1].

It is absolutely obvious that in order to provide the ecology of mining transport operational environment, all possible negative aspects of its operation have to be identified. Besides, the mechanism of their quantitative assessment is to be developed, and potential ways to diminish them are to be determined. The analysis of technological processes of mining transport operation allows us to distinguish the following negative aspects:

- the high level of a negative impact on the environment as a result of harmful emissions into the atmosphere, and the hazard of excess of their maximum concentration limits (MCL) at work sites;

- mining transport accidents (excavators and mine dump trucks), threatening employees' health and life.

Further, the mechanism of their quantitative assessment is to be developed. It should be taken into account that the quantitative measure of the negative aspects has to assess the probability of their emergence, as well as the possible damage from them [12]. The basic propositions of risk theory can be used to solve the given problem. Federal law № 184-FZ «On technical regulation» was enacted in the Russian Federation on December 27, 2002. On the basis of national and international experience, the law forms a unified database of assessment methods, as well as the risk management of various technosphere objects, including mining transport. The basic provisions of the law allow us to form the concept of technogenic risks of a mining transport complex, which is defined as an integral hazard measure, characterizing the possibility of damage and its expected extent. In the systematic approach, risk assessment is a number of logical steps, which enable us to consider all hazard factors in a systematic way.

Thus, by adapting the basic provisions of Law № 184-FZ «On technical regulation» for the problem solvation, the central position in the concept, being-developed, is the technogenic risk function of a mining transport complex, which, in its structure, links the probability of negative aspect emergence with mathematical expectation of the damage from the mentioned aspects. The technogenic risk function of a mining transport complex can be described as

$$
R_{G T K}=F_{R}\left\{P_{G T K}, U_{G T K}\right\},
$$

where $P_{G T K}$ is the probability of negative aspects emergence as a result of mining transport operation; $U_{G T K}$ is the mathematical expectation of the damage from the emergence of the respective negative aspect of mining transport operation.

Complicated dynamic nonlinear models of the probability of negative aspects emergence are required to be developed on the basis of equation (1) for the qualitative and quantitative analysis of mining transport technogenic risks [13]. According to equation (1), damage $U_{G T K}$ and risks $R_{G T K}$, respectively, are determined by a large number of indicators. At the current stage, the given measurements of the negative aspects of mining transport 
operation can be assessed by two indicators: economic - in rubles (conventional unit), and the one, in human casualties (both fatal and nonfatal).

The selection of the methods of technogenic risk assessment is determined by the following major factors [14]:

- initial potential hazard of mining transport complexes;

- the increasing probability of the emergence of negative aspects of mining transport operation;

- the availability or the development of source databases for computational-experiment evaluation of functionals $F$ and parameters $P_{G T K}$ and $U_{G T K}$ of the technogenic risks of mining transport complexes in compliance with equation (1).

Statistical and probabilistic methods can be used as initial for mining transport complexes [14]. Uncontrollable release of energy in the case of a mining transport accident $E$, as well as controlled emissions of harmful substances into the atmosphere $W$, appears as a hazard source. Respectively, the extent of the negative aspect emergence has to be analyzed for each hazard source:

- the volume of released energy $E$, energy concentration $d E / d F$, the rate (impulse) of energy release $d E / d t$;

- mass $W$, concentration $d W / d F$ and the dose of harmful substances $(d W / d F) d t$ (here, $F$ is the area of the negative aspect emergence).

Critical values $E_{c}, W_{c}$, maximum concentration limits $[E]$, [W] hazard sources with their assigned maximum concentration limits $[d E / d F],[d W / d F]$ doses $[(d E / d F) d t],[(d W / d F) d t]$, the degree of vulnerability $V$, and damage $D$ are to be analyzed for each negative aspect [15].

For combinations of negative aspects and maximum permissible values of hazard sources, probabilistic modelling and integration (summing) are carried out, taking into account the functions of distribution over area $F$ within time $t$, in order to evaluate technogenic risks $R_{G T K}$, damage $D$ or vulnerability $V$ through the ratios of current values of hazardous energies and substances (or their concentrations and doses) to the critical ones:

$$
\left\{D_{F, t}, V_{F, t}\right\}=F_{D, V}\left\{\left(E / E_{c}\right),\left(W / W_{c}\right)\right\} .
$$

The values of detriment $U_{G T K}$ over the area $F$ within time $t$ are estimated by the calculated values of damage $D_{F, t}$ and vulnerability $V_{F, t}$ for given probabilities $P_{G T K}$. Calculated values $P_{G T K(F, t)}$ and $U_{G T K(F, t)}$ enable us to determine technogenic risks $R_{G T K(F, t)}$ for the given area $F$ and time $t$. With the availability of science-based maximum permissible values of technogenic risks $\left[R_{G T K}\right]$ or $\left[R_{G T K(F, t)}\right]$, the safety condition can be presented as

$$
\left\{R_{G T K}, R_{G T K(F, t)}\right\} \leq\left\{\left[R_{G T K}\right],\left[R_{G T K(F, t)}\right]\right\} \text {. }
$$

While solving the direct problem of providing integral safety, according to condition (3), permissible values $\left[R_{G T K}\right]$ and $\left[R_{G T K(F, t)}\right]$ are set, using permissible values $[E]$ and $[W]$ or their concentrations and doses. While solving the inverse problem with the given values of technogenic risks $\left[R_{G T K}\right]$ and $\left[R_{G T K(F, t)}\right]$, maximum permissible values $[E]$ and $[W]$ or their concentrations and doses can be calculated.

Transport risk management, taking into account condition (3), is to execute, within vehicle control, a complex of three main measures:

- to assess technogenic risks $\left\{R_{G T K}, R_{G T K(F, t)}\right\}$ scientifically, using computationalexperimental methods;

- to justify the maximum concentration limits of technogenic risks $\left\{\left[R_{G T K}\right],\left[R_{G T K(F, t)}\right]\right\}$, taking into account national and international experience;

- to work out measures with necessary expenses $Z$ and their efficiency (efficiency coefficients $m_{z}$ ) for providing the assigned level of mining transport safety.

Therefore, the general problem of technogenic risk management and assessment has the following form

$$
\left\{R_{G T K}, R_{G T K(F, t)}\right\} \leq\left\{\left[R_{G T K}\right],\left[R_{G T K(F, t)}\right]\right\}=F_{Z}\left\{m_{z}, Z\right\} .
$$


In order to present the detailed structure of mining transport technogenic risks by its components - probabilities $P_{G T K}$ and detriment $U_{G T K}$ from the emergence of negative aspects of mining transport operation, taking into account condition (1), it is necessary to select and analyze the statistical data on the emergence of negative aspects of mining transport operation within preceding period $\Delta t$. $\Delta t$ is assumed as equal to 1 for the preceding period or sequence of previous years $-2,3,4, \ldots n$. The higher the quantitative value of $\Delta t$ is, the more objective the obtained results are.

The proposed concept of technogenic risks gives the principal basis for planning the measures of providing the required ecology of mining transport operational environment. Initial data for calculation are:

- statistical data on mining transport accidents within the preceding period $\Delta t$, pointing their location (to specify area $F$ );

- mining transport emission data for the following calculation of actual concentrations of harmful substances in the atmosphere over area $F$.

In order to enhance the objectivity of defining the level of technogenic risks, the procedures of its component identification should be detailed. Based on the above mentioned negative aspects of mining transport operation, the general level of technogenic risks includes the level of risk in terms of mining transport accidents, and the level of risk in terms of harmful emission into the atmosphere, which leads to the excess of their MCL. This technogenic risk structure can be represented as the following formula

$$
R_{G T K}=R_{G T K}^{I}+R_{G T K}^{V}
$$

where $R_{G T K}{ }^{I}$ is the technogenic risk level in terms of accidents; $R_{G T K}{ }^{V}$ is the technogenic risk level in terms of harmful emissions, which leads to the excess of their MCL in the atmosphere of mining transport complexes.

The stated postulates and the principles of the developed concept of technogenic risks are the basis for the development of practical methodology of providing the required ecology of mining transport operational environment. Summarizing the proposed provisions, the corresponding methods can be implemented in stages, the sequence of which is shown in fig. 1.

According to the methodology, shown in fig.1, the quantitative values of probability $P_{G T K}$ and detriment $U_{G T K}$ have to be substantiated. The probability of accidents is evaluated on the basis of operating time (either in hours or in kilometers) to the moment of accident, and the detriment is estimated in compliance with the data on fatal and nonfatal casualties.

While estimating the probability of impermissible harmful emissions into the atmosphere, in the first instance, the emission data of a mine dump truck, as the main source of harmful emissions, are to be determined [16], [17]. To a first approximation, the emission data of mine dump trucks $T_{K A}$ can be presented as functional $F_{T}$ with a sum vector of original variables in the following form [17], [18]

$$
T_{K A}=F_{T}\left\{X_{D}, X_{A}, X_{G}\right\}
$$

where $X_{D}$ is the original vector of variables, determined by engine parameters; $X_{A}$ is the original vector of variables, determined by the design of a dump truck, in general; $X_{G}$ is the original vector of variables, determined by geometric parameters of mining transport communication lines.

Original vector $X_{D}$ is determined by engine design features (type, fuel used, capasity, power, combustion chamber features, technical condition, systems of emission reduction, and etc.) [18], [19]. Original vector $X_{A}$ is determined by the design of a dump truck, in general (truck mass, carrying capacity, transmission, technical condition, and etc.) [19], 
[20]. Original vector $X_{G}$ is determined by geometric parameters of mining transport communication lines (longitudinal gradients, radius of curves, length of tangent level tracks, and etc.), and it exerts direct influence on the mode of dump truck driving [16], [17], [19], [20]. At a given volume of transportation, the more unstable truck driving becomes, the higher harmful emission is.

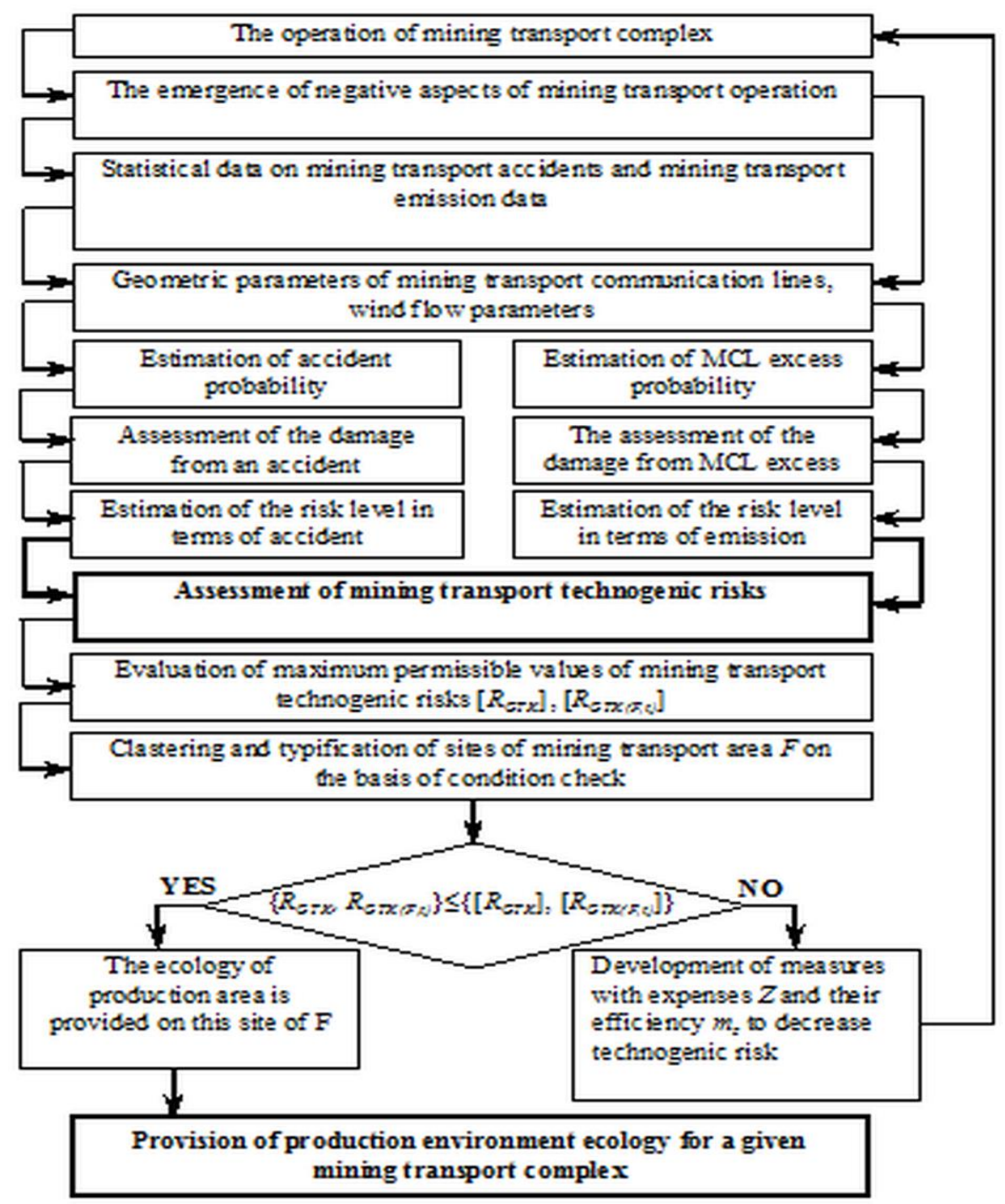

Fig. 1. The methodology of providing the required ecology of mining transport operational environment

At the same time, the level of risk from an impermissible harmful emission is assessed by the concentration of harmful substances in the atmosphere. As a result, prevailing meteorological parameters, influencing the diffusion of harmful substances in the atmosphere, are to be imposed on the emission data of mine dump trucks $T_{K A}$. Meteorological parameters primarily include wind flow parameters (wind rose, average wind speed, wind gustiness) [1], [2]. In this case, the lower the wind speed and gustiness, 
the worse the diffusion of harmful substances in the atmosphere, and the higher the probability of MCL excess.

The value of the detriment from an impermissible harmful emission is estimated by calculating economic losses as a result of air contamination in operational environment of mining transport.

On the basis of the procedures, described above, the quantitative values of $R_{G T K}{ }^{I}$ and $R_{G T K}{ }^{V}$ are estimated by equation (5). It enables us to assess the integral level of technogenic risk $R_{G T K}$ as the main criterion for designing measures of providing the required ecology of mining transport operational environment. To this effect, $F$ sites of mining transport complexes have to be clustered according to their homogeneity of operational environment conditions and values of technogenic risks $\left\{R_{G T K}, R_{G T K(F, t)}\right\}$. At that, $F$ sites with permissible and impermissible levels of technogenic risks are typified (ranked) on the basis of condition (3) check. Necessary measures with expenses $Z$ are developed for $F$ sites with an impermissible level of technogenic risk in order to lower the level of technogenic risk. After the measures being practically implemented, the efficiency of expenses $m_{z}$ is valued. Further, condition (3) is checked for all $F$ sites, where the level of technogenic risk is impermissible. Therefore, the provision of the required ecology of mining transport operational environment is an iterative process, which is repeated till there are no $F$ sites with an impermissible level of technogenic risk left.

In conclusion, the implementation of the concept of mining transport technogenic risk can lead to the improvement of the ecology of mining transport operational environment, and, eventually, to the realization of the principle of ecological compatibility and population health for successful fulfilment of the Strategy of socio-economic development of Kemerovo region, also referred as Kuzbass, for the period to 2035.

The work is executed within the limits of the complex scientific and technical program of a full innovative cycle "Development and introduction of a complex of technologies in areas of exploration and extraction of solid minerals, maintenance of industrial safety, bioremediation, creation of new products of deep processing from coal raw materials at consecutive decrease in ecological impact on environment and risks for population life" (CSTP "Clean coal - Green Kuzbass") on event 2.5 "Development and creation of an autonomous shuttle-type dump truck with carrying capacity of 220 tons (JUPITER project)", with participation of T.F. Gorbachev Kuzbass State Technical University in terms of research, development and technological works.

\section{References}

1. V.G. Mikhailov, G.S. Mikhailov, A.G. Koryakov, Journal of mining science 5, 930 (2015)

2. G.V. Kalabin, Journal of mining science 6, 1071 (2012)

3. V.E. Forbes, N. Galic, Environment international 91, 215 (2016)

4. Z. Long, Y. Huang, W. Zhang, Y. Chen, C. Liu, R. Wang, Z. Shi, D. Yu, Environmental monitoring and assessment 1, 20 (2021)

5. L.A. Kapustka, J. Yocum, H. Galbraith, M. Luxon, Toxicology and industrial health 10, 236 (2001)

6. A. Urzelai, M. Vega, E. Angulo, The science of the total environment 2-3, 279 (2000)

7. B.L. Preston, T.W. Snell, Environment pollution 3, 399 (2001)

8. R.A. Efroymson, D.L. Murhy, The science of the total environment 1-3, 219 (2001)

9. M. Baoyan, Z. Xuelin, The science of the total environment 1-2, 103 (2000)

10. D.A. Haith, Environment science and technology 16, 6496 (2010) 
11. F. Picado, G. Bengtsson, A. Mendoza, G. Barmen, S. Cuadra, K. Jakobsson, Risk Analysis 6, 916 (2010)

12. H. Shi, W. Zheng, Disaster Advances 4, 110 (2010)

13. B.L. Preston, Environment pollution 3, 431 (2002)

14. K. Modis, K.I. Vitalis, Soil and sediment contamination 1, 63 (2013)

15. M. Toktar, F.E. Kozybayeva, G. Lo Papa, C. Dazzi, Ecological Engineering 86,1 (2016)

16. Dmitry Dubinkin, Alexander Kulpin, and Dmitry Stenin, E3S Web of Conferences 174, 03015 (2020)

17. Alexander Kartashov, Boris Kositsyn, George Kotiev, Sergey Nazarenko, and Dmitry Dubinkin, E3S Web of Conferences 174, 03009 (2020)

18. Dubinkin D., Aksenov V., Tyulenev M., Markov S., Journal of mining and geotechnical engineering 4, 42 (2020)

19. Chicherin I.V., Fedosenkov B.A., Syrkin I.S., Sadovets V.Iu., Dubinkin D.M., Gornyi zhurnal. News of the Higher Institutions. Mining Journal 8, 109 (2020)

20. S.G. Kostyuk, B.A. Fedosenkov, I.V. Chicherin, D.M. Dubinkin. Sustainable development of mountain territories 4, 600 (2020) 